\title{
Motor planning of vertical arm movements in healthy older adults: does effort optimization persist with aging?
}

Gabriel Poirier ${ }^{1}$, Charalambos Papaxanthis ${ }^{1}$, France Mourey ${ }^{1}$, Jeremie Gaveau ${ }^{1}$

1. INSERM U1093-CAPS, Université Bourgogne Franche-Comté, UFR des Sciences du Sport, F-21000 Dijon, France

Corresponding author: jeremie.gaveau@u-bourgogne.fr

\section{ORCID}

- G. Poirier: https://orcid.org/0000-0002-4005-114X

- C. Papaxanthis: https://orcid.org/0000-0003-1955-8269

- F. Mourey: https://orcid.org/0000-0002-4526-6561

- J. Gaveau: https://orcid.org/0000-0001-8827-1486

Keywords: kinematics, aging, motor planning, effort, gravity, optimal control

\section{Acknowledgments}

This work was supported by the Institut National de la Santé et de la Recherche Médicale (INSERM) and by the Agence National de la Recherche (ANR, project MOTION ANR-14CE30-0007-01). We thank Cyril Sirandré and Yves Ballay for their technical support.

\section{Competing interests}

The authors declare no competing financial or non-financial interests. 


\begin{abstract}
Several sensorimotor modifications are known to occur with aging, possibly leading to adverse outcomes such as falls. Recently, some of those modifications have been proposed to emerge from motor planning deteriorations. Motor planning of vertical movements is thought to engage an internal model of gravity to anticipate its mechanical effects on the body-limbs and thus to genuinely produce movements that minimize muscle effort. This is supported, amongst other results, by direction-dependent kinematics where relative durations to peak accelerations and peak velocity are shorter for upward than for downward movements. The present study compares motor planning of fast and slow vertical arm reaching movements between eighteen young ( $24 \pm 3$ years old) and seventeen older adults (70 \pm 5 years old). We found that older participants still exhibit directional asymmetries (i.e., differences between upward and downward movements), indicating that optimization processes during motor planning persist with healthy aging. However, the size of these differences was increased in older participants, indicating that gravity-related motor planning changes with age. We discuss this increase as the possible result of an overestimation of gravity torque or increased weight of the effort cost in the optimization process. Overall, these results support the hypothesis that feedforward processes and, more precisely, optimal motor planning, remain active with healthy aging.
\end{abstract}




\section{Introduction}

Aging is associated with various sensorimotor modifications. Vision (Owsley 2011), vestibular function (Alberts et al. 2019), and proprioception (Goble et al. 2009) decline progressively. Walking and balance control are impaired (Laughton et al. 2003), and upperlimb arm movements become slower and more variable (Yan et al. 1998). These sensorimotor alterations lead to adverse effects such as falls, the most frequent cause of injuries in older adults (Grisso et al. 1990; World Health Organization. Ageing and Life Course Unit. 2008; Robinovitch et al. 2013). Because the number of older adults has fiercely increased in the past few decades, understanding the mechanisms responsible for age-related sensorimotor alterations is paramount.

Motor planning is a brain process specifying how a movement will be performed. Given a motor goal - e.g., grasping a cup of coffee - and a set of constraints - e.g., the gravitational pull on the arm and cup - this process selects the movement trajectory to be accomplished amongst a myriad of possible trajectories that would all attain the desired goal (Franklin and Wolpert 2011; Wong et al. 2015). For example, previous studies have shown that motor planning adapts reaching trajectories to changing inertial and gravitational constraints in young adults (Gaveau and Papaxanthis 2011; Vu et al. 2016a). There are pieces of evidence suggesting that aging alters motor planning (Kanekar and Aruin 2014; Kubicki et al. 2016; Casamento-Moran et al. 2017; Wunsch et al. 2017; Stöckel et al. 2017), and that altered motor planning may cause falls (Lord and Fitzpatrick 2001; Lyon and Day 2005; Robinovitch et al. 2013; Tisserand et al. 2016). Since fall is inherently linked to gravity, understanding how older adults adapt their motor planning to gravity is crucial.

Using arm reaching tasks, several studies have investigated gravity-related motor planning in young adults (Gentili et al. 2007; Le Seac'h and McIntyre 2007; Crevecoeur et al. 2009; Gaveau et al. 2011, 2014, 2016; Bringoux et al. 2012; Sciutti et al. 2012; Yamamoto and Kushiro 2014; Yamamoto et al. 2016, 2019; Hondzinski et al. 2016; Olesh et al. 2017). A consistent outcome is the existence of direction-dependent arm kinematics in normal gravity, which progressively disappears in microgravity (Papaxanthis et al. 2005; Gaveau et al. 2016). Direction-dependent kinematics is demonstrated by shorter time to peak acceleration and time to peak velocity for upward than for downward movements, i.e., more abrupt acceleration and softer deceleration. Model simulations explain these direction-dependent kinematics, and their progressive disappearance under microgravity conditions, as an optimization process that saves muscle effort (Berret et al. 2008; Crevecoeur et al. 2009; Gaveau et al. 2014, 2016). In 
young adults, direction-dependent kinematics has been proposed to represent the signature of a motor planning strategy that optimally integrates gravity torque to save muscle effort. Recent electromyographic (EMG) analyses further support this concept (Gaveau et al. 2019).

Here, relying on the above-described robust findings, we investigated the motor planning of vertical arm movements in young and healthy older adults. By comparing arm trajectories between upward and downward movements, we aimed to test whether older adults, like young ones, employ a motor planning strategy that optimally integrates gravity torque to save muscle effort.

\section{Methods}

\section{Ethics and participants}

This study was carried out following legal requirements and international norms (Declaration of Helsinki, 1964) and approved by the French National ethics committee (2019-A01558-49). Eighteen young (mean age $=24 \pm 3$ years; 14 males) and seventeen healthy older adults (mean age $=70 \pm 5$ years; 6 males) participated in this study after giving their written informed consent. All participants were right-handed, according to Edinburgh handedness inventory (Oldfield 1971), and did not present any neurological or musculoskeletal deficiency.

\section{Experimental design}

Our experimental devices and protocol were similar to those of previous studies investigating motor planning of arm movements in the gravity field (Gentili et al. 2007; Gaveau et al. 2011, 2014, 2016). We investigated single-degree-of-freedom arm movements to manipulate the effects of gravity (with movement direction) while keeping the rest of the movement dynamics constant (inertial forces). Single degree-of-freedom movements allow to specifically investigating gravity-related motor strategies. Participants were comfortably seated on a chair with their trunk in a vertical position. The target system (a curved steel bar with 3 targets fixed on it) was vertically aligned and placed in front of the participants' right arm at a distance equal to the length of their fully extended arm plus two centimeters (Figure 1A). We horizontally aligned the central target (starting target) with the participants' shoulder, while positioning the other two targets to imply a $30^{\circ}$ upwards or a $30^{\circ}$ downwards shoulder rotation. Starting from the central target, participants performed single-degree-of- 
freedom (rotation around the shoulder joint) upward and downward arm movements, as accurately as possible at two speeds. Previous work revealed that movement speed significantly influences the temporal organization of vertical arm movements (Gaveau and Papaxanthis 2011). Therefore, to obtain movements of comparable durations between conditions and groups, automatic online analyses of movement duration were performed, and the results were used to provide verbal feedback to the participants. This feedback aimed at driving participants to perform reaching movements lasting about 350ms (called fast speed below) and 550ms (called slow speed below). Fast and slow trials were performed in a random block design, and upward and downward movements were randomly ordered within each block (12 trials $\times 4$ conditions; 48 trials overall for each participant). Participants performed a few practice trials before the beginning of the experiment $(\sim 10$ practice trials per experimental condition). At the beginning of each trial, they were invited to point at the central target (starting position, see Fig. 1A). After a short period $(\sim 2 s)$, the experimenter verbally indicated the target (upward or downward) to reach. Participants were then allowed to carry out the movement without any constraint on their reaction time and to maintain their final finger position for about 2 seconds until a verbal signal informed them to relax their arm. In order to avoid muscle fatigue, we separated each trial by a short rest period $(\sim 15 \mathrm{~s})$ and both blocks by a five minutes rest period.

We placed five reflective markers on the participants' right shoulder (acromion), arm (middle of the humeral bone), elbow (lateral epicondyle), wrist (cubitus styloid process), and finger (nail of the index). We recorded markers' position with an optoelectronic motion capture system (VICON system) that consisted of six cameras (sampling frequency: 100Hz; precision $<0.5 \mathrm{~mm})$.

\section{Data analysis}

Data were processed using custom programs written in Matlab (Mathworks, Natick, MA). The tridimensional position (X, Y, Z) of markers was low-pass filtered with a digital thirdorder Butterworth filter (zero-phase distortion) at a cut-off frequency of $10 \mathrm{~Hz}$. We derived these signals in order to compute velocity and acceleration profiles for each movement. Movement start and end was defined as the moment when finger velocity respectively went above or fell below 10\% of the peak velocity value (Gaveau and Papaxanthis 2011; Gaveau et al. 2014, 2016). Movement duration and amplitude were computed based on movement start and end. 
Following results from previous studies, we quantified the temporal organization of each movement with two temporal parameters that are theoretically independent of the movement duration (see Figure 1B and Gaveau et al., 2011, 2014); i) the relative duration to peak acceleration (rD-PA), defined as the duration to peak divided by movement duration; ii) the relative duration to peak velocity (rD-PV), defined as the duration to peak velocity divided by movement duration.

\section{Statistical analysis}

We used STATISTICA 10 (StatSoft. Inc.) to perform all statistical analyses. All variables showed a normal distribution (Kolgomorov-Smirnov test). We carried out repeated measures variance analysis (three-way ANOVA) with 3 factors: age (Young vs Older), speed (Fast and Slow), and direction (Upward vs. Downward). We used Scheffé tests for post hoc comparisons. The level of significance was set at $\mathrm{p}<0.05$ for all analyses.

\section{Results}

Participants accurately reached targets (average movement amplitude: $28.8 \pm 1.1^{\circ}$ for young and $28.7 \pm 2.1^{\circ}$ for older participants, see Table 1 for all values) with smoothed movement exhibiting single-peaked and bell-shaped velocity profiles (Kelso et al. 1979). Figure 2 qualitatively illustrates the mean position, velocity, and acceleration profiles recorded for each group and direction at the fast speed.

Movement Duration. Because movement duration was previously shown to influence the temporal organization of arm movements (Gaveau and Papaxanthis 2011), to ensure that it was similar between conditions, we performed the same statistical analysis on movement duration as on the other parameters. As required by task constraints, movement duration significantly varied with speed instructions (speed effect: $F=105.18 ; \mathrm{p}<0.001 ; \eta_{\mathrm{p}}{ }^{2}=0.76$ ). Average movement durations were respectively $340 \pm 40 \mathrm{~ms}$ and $575 \pm 120 \mathrm{~ms}$ for fast and slow movements (Table 1$)$. However, neither age $\left(F=0.27 ; p=0.60 ; \eta_{p}{ }^{2}=0.008\right)$ nor direction $\left(\mathrm{F}=0.001 ; \mathrm{p}=0.97 ; \eta_{\mathrm{p}}{ }^{2}<0.001\right)$ effects were observed. Similarly, all interaction effects (age $\times$ direction, $\mathrm{F}=0.39 ; \mathrm{p}=0.53 ; \eta_{\mathrm{p}}{ }^{2}=0.01 ;$ speed $\times$ age, $\mathrm{F}=0.06 ; \mathrm{p}=0.81 ; \eta_{\mathrm{p}}{ }^{2}=$ 0.001 ; speed $\times$ direction, $\mathrm{F}=0.016 ; \eta_{\mathrm{p}}{ }^{2}<0.001 ; \mathrm{p}=0.90 ;$ age $\times$ speed $\times$ direction, $\mathrm{F}=0.10 ; \mathrm{p}$ $\left.=0.92 ; \eta_{\mathrm{p}}{ }^{2}<0.001\right)$ were non-significant. These results show that movement duration was similar between groups and directions within each speed instruction. 
Relative Duration to Peak Acceleration (rD-PA). Figure 3A and B displays rD-PA for each group, speed, and direction (see also Table 1). rD-PA was smaller for upward than for downward movements (direction effect, $\mathrm{F}=67.95 ; \mathrm{p}<0.001 ; \eta_{\mathrm{p}}{ }^{2}=0.67$ ). Comparison between Figure $3 \mathrm{~A}$ and $\mathrm{B}$ also reveals that rD-PA was smaller for slow than for fast movements (speed effect, $\mathrm{F}=40.64 ; \mathrm{p}<0.001 ; \eta_{\mathrm{p}}{ }^{2}=0.55$ ). Of particular interest for the present study is the fact that the difference between upward and downward movements was larger in the older than in the young adults at both speeds. The ANOVA yielded a significant age $\times$ direction interaction effect $\left(\mathrm{F}=4.41 ; \mathrm{p}=0.04 ; \eta_{\mathrm{p}}{ }^{2}=0.12\right)$ but no age $\times$ speed $\times$ direction interaction $\left(\mathrm{F}=0.003 ; \mathrm{p}=0.95 ; \eta_{\mathrm{p}}{ }^{2}<0.001\right)$. Box-plot in Figure $3 \mathrm{C}$ presents the ratio of directional difference ((Down-Up)/Down) to further illustrate the effect of age and speed on direction-dependent kinematics.

Relative Duration to Peak Velocity ( $r D-P V)$. As for $\mathrm{rD}-\mathrm{PA}$, the relative duration to peak velocity was shorter for upward compared to downward movements $(\mathrm{F}=20.21$; $\left.\mathrm{p}<0.001 ; \eta_{\mathrm{p}}{ }^{2}=0.38\right)$ and for slow compared to fast movements $\left(\mathrm{F}=4.98 ; \mathrm{p}=0.03 ; \eta_{\mathrm{p}}{ }^{2}=\right.$ 0.13; see Table 1). Also, the age $\times$ direction interaction yielded a significant effect $(\mathrm{F}=9.21$; $\mathrm{p}=0.005 ; \eta_{\mathrm{p}}{ }^{2}=0.22$ ), further supporting the increased directional asymmetry in older compared to young adults. As for the rDPA, the age $\times$ speed $\times$ direction interaction did not reach significance $\left(\mathrm{F}=0.02 ; \mathrm{p}=0.90 ; \eta_{\mathrm{p}}^{2}<0.001\right)$.

\section{Discussion}

We investigated the motor planning of single-degree-of-freedom vertical arm movements in young and older adults. Precisely, we compared directional asymmetries (the difference between upwards and downwards) on relative durations to peak acceleration and peak velocity. Our results show increased directional asymmetries on both parameters in older participants compared to young ones.

In young adults, several studies have shown that single-degree-of-freedom arm movements exhibit directional asymmetries in the vertical plane. These asymmetries: i) were consistently reported as a more abrupt acceleration phase for upward than for downward movements; ii) do not exist in the horizontal plane (Gentili et al. 2007; Le Seac'h and McIntyre 2007); iii) progressively disappear in the vertical plane when participants are exposed to microgravity (Papaxanthis et al. 2005; Gaveau et al. 2016); iv) were observed very early in the movements (before 70ms after movement start (Gaveau and Papaxanthis 2011; Gaveau et al. 2014); v) were explained by optimal control model simulations and EMG 
analyses as a motor strategy that minimizes muscle effort (Berret et al. 2008; Crevecoeur et al. 2009; Gaveau et al. 2014, 2016, 2019). Altogether, in young adults, previous results strongly suggest that direction-dependent kinematics represent the signature of a motor planning strategy that optimally integrates gravity torque to save muscle effort. The present results reveal that older adults also produce directional asymmetries in the vertical plane. Most importantly, these asymmetries have the same sign as those of young adults - a more abrupt acceleration for upward than for downward movements - and they emerge early in the movement - rD-PA was already different, which is about $70 \mathrm{~ms}$ after movement onset at the fastest speed -. First, this reveals that older adults, similar to young adults, plan arm movements that are direction-dependent in the gravity field. Second, the present results suggest that optimal motor planning, and more specifically, the minimization of muscle effort, continue with healthy aging. Indeed, although the size of the directional asymmetry was shown larger in older compared to young adults, previous studies have demonstrated that the simple existence of the directional asymmetry - independently of its size - is sufficient to reveal an effort-related optimization process (Berret et al. 2008; Gaveau et al. 2016). Hereafter, building on recent experimental and modeling results, we discuss the increased direction-dependence of arm kinematics in older adults.

Studying motor planning within the optimal control framework, previous works explained human movement as the minimization of composite cost functions (for a recent review, see Berret et al. 2019). For example, minimizing a trade-off between effort and smoothness allowed to explain how reach endpoint is selected during multi-articular arm movement tasks (Berret et al. 2011; Vu et al. 2016b). Using an effort and smoothness composite cost function, the model simulations from Gaveau et al. (2016) also demonstrated that increasing the weight of the effort cost produces an increase in directional asymmetries. Thus, the increased importance of effort during motor planning could explain the increased directional asymmetry observed in older adults. Indeed, aging is associated with a loss of muscle mass and strength (for a review, see Mitchell et al. 2012) that likely results in an increased perception of effort for daily-life tasks (McCloskey et al. 1974; Hess et al. 2016; Pageaux and Lepers 2016).

Experimental and modeling results have also demonstrated that the size of the directional asymmetry is proportional to the gravity torque (Gaveau et al. 2014, 2016). Increasing the gravity torque either by moving body limbs of increasing mass (i.e., upper arm, forearm, and wrist) or by adding an external load on the limb both led to increased directional asymmetries in the vertical plane (Gaveau et al. 2014). Progressively varying movement 
direction relative to gravity caused a progressive variation of the temporal organization of arm movement such that arm kinematics and gravity torque linearly correlated with each other (Gaveau et al. 2016). Last, during exposure to microgravity, model simulations explained the progressive disappearance of directional asymmetries as the progressive decrease of the gravity value, i.e., a recalibration of the internal gravity model (Gaveau et al. 2016). Thus, the anticipation of an increased gravity torque could explain the increased directional asymmetry observed in older adults. Experiments on object weight perception in older adults have provided support for such an overestimation of gravity torque (Parikh and Cole 2012; Holmin and Norman 2012). Assuming that motor control is the result of two parallel processes, a forward model that produces accurate motor output and an optimal controller selecting the trajectories that minimize some hidden motor costs (Izawa et al. 2008), over-estimating gravity torque would lead to new optimal trajectories without impeding movement accuracy (Gaveau et al. 2011).

Sensory information about gravity is known to influence motor planning (Bringoux et al. 2012; Rousseau et al. 2016). With aging, several studies have provided evidence for sensory deterioration in visual (see Saftari and Kwon (2018) for a review), proprioceptive (Goble et al. 2009), and vestibular systems (Alberts et al. 2019), as well as their multisensory weighting (de Dieuleveult et al. 2017). The perception of gravity vertical also deteriorates with aging (Kobayashi et al. 2002; Baccini et al. 2014). One may, therefore, wonder whether an alternative hypothesis for increased directional asymmetry in older adults could be the elderly's' failure to measure gravity torque. In other words, one may expect older adults to apply the same motor plan for vertical and horizontal movements. This premise is implausible as it would produce either no directional asymmetry (Gentili et al. 2007; Le Seac'h and McIntyre 2007) - should the forward model be accurate - or extensive end-point errors and directional asymmetries with an opposite sign - should the forward model be inaccurate We observed none of those effects in the present study. Conversely, it is crucial to underline that we observed similar results for $\mathrm{rD}-\mathrm{PA}$ and $\mathrm{rD}-\mathrm{PV}$. Also, we observed no interaction and small effect sizes of age $\times$ speed $\times$ direction, indicating that speed did not influence the age effect on directional asymmetries. Since rD-PV happens late in the movement, especially at slow speed (about 250ms after onset), our results suggest that no online feedback-driven correction was implemented to address hypothesized motor planning errors.

The present results add to the existing literature suggesting that motor planning is modified with aging (Kanekar and Aruin 2014; Kubicki et al. 2016; Casamento-Moran et al. 2017; Wunsch et al. 2017; Stöckel et al. 2017). Neuroscientists have first interpreted motor 
planning modifications as a deterioration of feedforward processes (proactive strategies) that urges older adults to favor feedback processes (reactive strategies). The most potent experimental support for this hypothesis is the general observation that movements become slower with aging (Buckles 1993; Yan et al. 1998). However, older adults are not always slower than younger adults. Asking participants to reach, grasp and lift an object at their own pace, Hoellinger et al. (2017) found that older adults moved faster than young adults. Comparing their empirical results to model simulations, the authors suggested that older adults planned stronger feedforward forces in order to favor feedforward mechanisms over feedback ones. This hypothesis is rooted in results showing that the sensory system becomes noisier with aging (Desmedt and Cheron 1980; Doherty et al. 1994; Stevens and Choo 1996). Thus, to compensate for their noisy unreliable sensory system, older adults may favor feedforward over feedback mechanisms. This hypothesis is well-supported by recent results showing that sensory attenuation, a well-studied feedforward mechanism (Blakemore et al. 1998; Shergill et al. 2005; Pareés et al. 2014), increases with aging (Wolpe et al. 2016). Results of neurobiological studies suggesting that increased brain activations compensate for neuro-behavioral deficits to preserve motor performance in older adults could also support the hypothesis of increased reliance on feedforward mechanisms (Cabeza 2002; Berchicci et al. 2012).

There are pieces of evidence suggesting that feedforward mechanisms remain functional with healthy aging and may even compensate for unreliable feedback mechanisms (Boisgontier and Nougier 2013; Wolpe et al. 2016; Helsen et al. 2016; Hoellinger et al. 2017; Vandevoorde and Orban de Xivry 2019). The result that older adults still plan directiondependent arm movements in the gravity field further supports and extends this hypothesis. The present study also reveals that aging exacerbates the direction-dependence of arm kinematics. This result constitutes the first insight into the effect of aging on gravity-related motor planning, whose better understanding may benefit the prevention and rehabilitation of falls and fallers in older adults. Indeed, although we investigated single degree of freedom arm movements to isolate gravity effects here, it is essential to mention that directional asymmetries are also documented for multi-articular arm reaching, reaching to grasp, grasping, hand drawing, and whole-body sit-to-stand / stand-to-sit movements (Papaxanthis et al. 1998, 2003, 2005; Yamamoto and Kushiro 2014). Future studies should attempt to extend the present findings to whole-body movement tasks and to disentangle sensory from motor planning modifications in older adults. 


\section{References}

Alberts BBGT, Selen LPJ, Medendorp WP (2019) Age-related reweighting of visual and vestibular cues for vertical perception. J Neurophysiol 121:1279-1288. https://doi.org/10.1152/jn.00481.2018

Baccini M, Paci M, Del Colletto M, et al (2014) The assessment of subjective visual vertical: comparison of two psychophysical paradigms and age-related performance. Attention, Perception, Psychophys 76:112-122. https://doi.org/10.3758/s13414-013-0551-9

Berchicci M, Lucci G, Pesce C, et al (2012) Prefrontal hyperactivity in older people during motor planning. Neuroimage 62:1750-1760. https://doi.org/10.1016/j.neuroimage.2012.06.031

Berret B, Chiovetto E, Nori F, Pozzo T (2011) Evidence for Composite Cost Functions in Arm Movement Planning: An Inverse Optimal Control Approach. PLoS Comput Biol 7:e1002183. https://doi.org/10.1371/journal.pcbi.1002183

Berret B, Darlot C, Jean F, et al (2008) The inactivation principle: Mathematical solutions minimizing the absolute work and biological implications for the planning of arm movements. PLoS Comput Biol 4:e1000194. https://doi.org/10.1371/journal.pcbi.1000194

Berret B, Delis I, Gaveau J, Jean F (2019) Optimality and Modularity in Human Movement: From Optimal Control to Muscle Synergies. Springer, Cham, pp 105-133

Blakemore S-J, Wolpert DM, Frith CD (1998) Central cancellation of self-produced tickle sensation. Nat Neurosci 1:635-640. https://doi.org/10.1038/2870

Boisgontier MP, Nougier V (2013) Ageing of internal models: From a continuous to an intermittent proprioceptive control of movement. Age (Omaha) 35:1339-1355. https://doi.org/10.1007/s11357-012-9436-4

Bringoux L, Blouin J, Coyle T, et al (2012) Effect of gravity-like torque on goal-directed arm movements in microgravity. J Neurophysiol 107:2541-2548. https://doi.org/10.1152/jn.00364.2011

Buckles VD (1993) Age-Related Slowing. In: Sensorimotor Impairment in the Elderly. Springer Netherlands, Dordrecht, pp 73-87 
Cabeza R (2002) Hemispheric asymmetry reduction in older adults: the HAROLD model. Psychol Aging 17:85-100

Casamento-Moran A, Chen Y-T, Lodha N, et al (2017) Motor plan differs for young and older adults during similar movements. J Neurophysiol 117:1483-1488. https://doi.org/10.1152/jn.00640.2016

Crevecoeur F, Thonnard J-L, Lefevre P (2009) Optimal Integration of Gravity in Trajectory Planning of Vertical Pointing Movements. J Neurophysiol 102:786-796. https://doi.org/10.1152/jn.00113.2009

de Dieuleveult AL, Siemonsma PC, van Erp JBF, Brouwer A-M (2017) Effects of Aging in Multisensory Integration: A Systematic Review. Front Aging Neurosci 9:80. https://doi.org/10.3389/fnagi.2017.00080

Desmedt JE, Cheron G (1980) Somatosensory evoked potentials to finger stimulation in healthy octogenarians and in young adults: Wave forms, scalp topography and transit times of pariental and frontal components. Electroencephalogr Clin Neurophysiol 50:404-425. https://doi.org/10.1016/0013-4694(80)90007-3

Doherty TJ, Komori T, Stashuk DW, et al (1994) Physiological properties of single thenar motor units in the F-response of younger and older adults. Muscle Nerve 17:860-872. https://doi.org/10.1002/mus.880170805

Franklin DW, Wolpert DM (2011) Computational mechanisms of sensorimotor control. Neuron 72:425-442

Gaveau J, Berret B, Angelaki DE, Papaxanthis C (2016) Direction-dependent arm kinematics reveal optimal integration of gravity cues. Elife 5:. https://doi.org/10.7554/eLife.16394

Gaveau J, Berret B, Demougeot L, et al (2014) Energy-related optimal control accounts for gravitational load: comparing shoulder, elbow, and wrist rotations. J Neurophysiol 111:4-16. https://doi.org/10.1152/jn.01029.2012

Gaveau J, Grospretre S, Angelaki D, Papaxanthis C (2019) A cross-species neural integration of gravity for motor optimisation. bioRxiv 728857. https://doi.org/10.1101/728857

Gaveau J, Paizis C, Berret B, et al (2011) Sensorimotor adaptation of point-to-point arm movements after spaceflight: the role of internal representation of gravity force in 
trajectory planning. J Neurophysiol 106:620-9. https://doi.org/10.1152/jn.00081.2011

Gaveau J, Papaxanthis C (2011) The Temporal Structure of Vertical Arm Movements. PLoS One 6:e22045. https://doi.org/10.1371/journal.pone.0022045

Gentili R, Cahouet V, Papaxanthis C (2007) Motor planning of arm movements is directiondependent in the gravity field. Neuroscience 145:20-32. https://doi.org/10.1016/j.neuroscience.2006.11.035

Goble DJ, Coxon JP, Wenderoth N, et al (2009) Proprioceptive sensibility in the elderly: Degeneration, functional consequences and plastic-adaptive processes. Neurosci Biobehav Rev 33:271-278. https://doi.org/10.1016/j.neubiorev.2008.08.012

Grisso JA, Schwarz DF, Wishner AR, et al (1990) Injuries in an Elderly Inner-City Population. J Am Geriatr Soc 38:1326-1331. https://doi.org/10.1111/j.15325415.1990.tb03456.x

Helsen WF, Van Halewyck F, Levin O, et al (2016) Manual aiming in healthy aging: does proprioceptive acuity make the difference? Age (Omaha) 38:45. https://doi.org/10.1007/s11357-016-9908-z

Hess TM, Smith BT, Sharifian N (2016) Aging and effort expenditure: The impact of subjective perceptions of task demands. Psychol Aging 31:653-660. https://doi.org/10.1037/pag0000127

Hoellinger T, McIntyre J, Jami L, et al (2017) A strategy of faster movements used by elderly humans to lift objects of increasing weight in ecological context. Neuroscience 357:384399. https://doi.org/10.1016/j.neuroscience.2017.04.010

Holmin JS, Norman JF (2012) Aging and Weight-Ratio Perception. PLoS One 7:e47701. https://doi.org/10.1371/journal.pone.0047701

Hondzinski JM, Soebbing CM, French AE, Winges SA (2016) Different damping responses explain vertical endpoint error differences between visual conditions. Exp Brain Res 234:1575-1587. https://doi.org/10.1007/s00221-015-4546-8

Izawa J, Rane T, Donchin O, Shadmehr R (2008) Motor Adaptation as a Process of Reoptimization. J Neurosci 28:2883-2891. https://doi.org/10.1523/JNEUROSCI.535907.2008 
Kanekar N, Aruin AS (2014) The effect of aging on anticipatory postural control. Exp Brain Res 232:1127-1136. https://doi.org/10.1007/s00221-014-3822-3

Kelso J, Southard D, Goodman D (1979) On the nature of human interlimb coordination. Science (80- ) 203:1029-1031. https://doi.org/10.1126/science.424729

Kobayashi H, Hayashi Y, Higashino K, et al (2002) Dynamic and static subjective visual vertical with aging. Auris Nasus Larynx 29:325-328. https://doi.org/10.1016/S03858146(02)00058-5

Kubicki A, Fautrelle L, Bourrelier J, et al (2016) The Early Indicators of Functional Decrease in Mild Cognitive Impairment. Front Aging Neurosci 8:193. https://doi.org/10.3389/fnagi.2016.00193

Laughton CA, Slavin M, Katdare K, et al (2003) Aging, muscle activity, and balance control: physiologic changes associated with balance impairment. Gait Posture 18:101-108. https://doi.org/10.1016/S0966-6362(02)00200-X

Le Seac'h AB, McIntyre J (2007) Multimodal reference frame for the planning of vertical arms movements. Neurosci Lett 423:211-215. https://doi.org/10.1016/j.neulet.2007.07.034

Lord SR, Fitzpatrick RC (2001) Choice Stepping Reaction Time: A Composite Measure of Falls Risk in Older People. Journals Gerontol Ser A Biol Sci Med Sci 56:M627-M632. https://doi.org/10.1093/gerona/56.10.M627

Lyon IN, Day BL (2005) Predictive control of body mass trajectory in a two-step sequence. Exp Brain Res 161:193-200. https://doi.org/10.1007/s00221-004-2058-z

McCloskey DI, Ebeling P, Goodwin GM (1974) Estimation of weights and tensions and apparent involvement of a "sense of effort." Exp Neurol 42:220-232. https://doi.org/10.1016/0014-4886(74)90019-3

Mitchell WK, Williams J, Atherton P, et al (2012) Sarcopenia, Dynapenia, and the Impact of Advancing Age on Human Skeletal Muscle Size and Strength; a Quantitative Review. Front Physiol 3:260. https://doi.org/10.3389/fphys.2012.00260

Oldfield RC (1971) The assessment and analysis of handedness: The Edinburgh inventory. Neuropsychologia 9:97-113. https://doi.org/10.1016/0028-3932(71)90067-4 
Olesh E V., Pollard BS, Gritsenko V (2017) Gravitational and Dynamic Components of Muscle Torque Underlie Tonic and Phasic Muscle Activity during Goal-Directed Reaching. Front Hum Neurosci 11:. https://doi.org/10.3389/fnhum.2017.00474

Owsley C (2011) Aging and vision. Vision Res. 51:1610-1622

Pageaux B, Lepers R (2016) Fatigue Induced by Physical and Mental Exertion Increases Perception of Effort and Impairs Subsequent Endurance Performance. Front Physiol 7:587. https://doi.org/10.3389/fphys.2016.00587

Papaxanthis C, Dubost V, Pozzo T (2003) Similar planning strategies for whole-body and arm movements performed in the sagittal plane. Neuroscience 117:779-783. https://doi.org/10.1016/S0306-4522(02)00964-8

Papaxanthis C, Pozzo T, McIntyre J (2005) Kinematic and dynamic processes for the control of pointing movements in humans revealed by short-term exposure to microgravity. Neuroscience 135:371-383. https://doi.org/10.1016/j.neuroscience.2005.06.063

Papaxanthis C, Pozzo T, Vinter A, Grishin A (1998) The representation of gravitational force during drawing movements of the arm. Exp Brain Res 120:233-242. https://doi.org/10.1007/s002210050397

Pareés I, Brown H, Nuruki A, et al (2014) Loss of sensory attenuation in patients with functional (psychogenic) movement disorders. Brain 137:2916-2921. https://doi.org/10.1093/brain/awu237

Parikh PJ, Cole KJ (2012) Handling objects in old age: forces and moments acting on the object. J Appl Physiol 112:1095-1104. https://doi.org/10.1152/japplphysiol.01385.2011

Robinovitch SN, Feldman F, Yang Y, et al (2013) Video capture of the circumstances of falls in elderly people residing in long-term care: an observational study. Lancet 381:47-54. https://doi.org/10.1016/S0140-6736(12)61263-X

Rousseau C, Papaxanthis C, Gaveau J, et al (2016) Initial information prior to movement onset influences kinematics of upward arm pointing movements. J Neurophysiol 116:1673-1683. https://doi.org/10.1152/jn.00616.2015

Saftari LN, Kwon O-S (2018) Ageing vision and falls: a review. J Physiol Anthropol 37:11. https://doi.org/10.1186/s40101-018-0170-1 
Sciutti A, Demougeot L, Berret B, et al (2012) Visual gravity influences arm movement planning. J Neurophysiol 107:3433-45. https://doi.org/10.1152/jn.00420.2011

Shergill SS, Samson G, Bays PM, et al (2005) Evidence for Sensory Prediction Deficits in Schizophrenia. Am J Psychiatry 162:2384-2386. https://doi.org/10.1176/appi.ajp.162.12.2384

Stevens JC, Choo KK (1996) Spatial acuity of the body surface over the life span. Somatosens Mot Res 13:153-66

Stöckel T, Wunsch K, Hughes CML (2017) Age-Related Decline in Anticipatory Motor Planning and Its Relation to Cognitive and Motor Skill Proficiency. Front Aging Neurosci 9:283. https://doi.org/10.3389/fnagi.2017.00283

Tisserand R, Robert T, Chabaud P, et al (2016) Elderly Fallers Enhance Dynamic Stability Through Anticipatory Postural Adjustments during a Choice Stepping Reaction Time. Front Hum Neurosci 10:613. https://doi.org/10.3389/fnhum.2016.00613

Vandevoorde K, Orban de Xivry J-J (2019) Internal model recalibration does not deteriorate with age while motor adaptation does. Neurobiol Aging 80:138-153. https://doi.org/10.1016/j.neurobiolaging.2019.03.020

$\mathrm{Vu} \mathrm{VH}$, Isableu B, Berret B (2016a) On the nature of motor planning variables during arm pointing movement: Compositeness and speed dependence. Neuroscience 328:127-146. https://doi.org/10.1016/j.neuroscience.2016.04.027

$\mathrm{Vu} \mathrm{VH}$, Isableu B, Berret B (2016b) Adaptive use of interaction torque during arm reaching movement from the optimal control viewpoint. Sci Rep 6:38845. https://doi.org/10.1038/srep38845

Wolpe N, Ingram JN, Tsvetanov KA, et al (2016) Ageing increases reliance on sensorimotor prediction through structural and functional differences in frontostriatal circuits. Nat Commun 7:. https://doi.org/10.1038/ncomms13034

Wong AL, Haith AM, Krakauer JW (2015) Motor Planning. Neurosci 21:385-398. https://doi.org/10.1177/1073858414541484

World Health Organization. Ageing and Life Course Unit. (2008) WHO global report on falls prevention in older age. World Health Organization 
Wunsch K, Weigelt M, Stöckel T (2017) Anticipatory motor planning in older adults.

Journals Gerontol - Ser B Psychol Sci Soc Sci 72:373-382.

https://doi.org/10.1093/geronb/gbv078

Yamamoto S, Fujii K, Zippo K, et al (2019) The kinetic mechanisms of vertical pointing movements. Heliyon 5:e02012. https://doi.org/10.1016/J.HELIYON.2019.E02012

Yamamoto S, Kushiro K (2014) Direction-dependent differences in temporal kinematics for vertical prehension movements. Exp Brain Res 232:703-711.

https://doi.org/10.1007/s00221-013-3783-y

Yamamoto S, Shiraki Y, Uehara S, Kushiro K (2016) Motor control of downward objecttransport movements with precision grip by object weight. Somatosens Mot Res 33:130136. https://doi.org/10.1080/08990220.2016.1203304

Yan JH, Thomas JR, Stelmach GE (1998) Aging and rapid aiming arm movement control. Exp Aging Res 24:155-168. https://doi.org/10.1080/036107398244292 


\section{Figure legends}

Figure 1: A. Experimental setup and participant's starting position. From this starting position, participants pointed to the upward or the downward target on separated trials. B. Illustration of the parameters computed on the velocity and acceleration profiles.

Table 1: Kinematic parameters for each condition. Mean $( \pm \mathrm{SD})$ movement duration (in $\mathrm{ms})$, amplitude (in ${ }^{\circ}$ ), relative duration to peak acceleration (rD-PA), and relative duration to peak velocity (rD-PV) are presented for each experimental condition.

Figure 2: Mean position (A-B), velocity (C-D), and acceleration (E-F) profiles for each group and direction at the fast speed. Black traces represent upward movements, and grey traces represent downward movements. Left panels display young participants' data, while right panels display older participants' data.

Figure 3: A. Mean ( \pm SD) relative duration to peak acceleration (rD-PA) for upward (black) and downward (grey) fast movements. Solid bars represent young, and striped bars represent older participants. B. Mean ( $\pm \mathrm{SD}$ ) relative duration to peak acceleration (rD-PA) for upward (black) and downward (grey) slow movements. Solid bars represent young, and striped bars represent older participants. C. Box plots show directional ratio (computed for each participant as: ((rD-PA $\left.\left.A_{\text {Down }}-\mathrm{rD}-\mathrm{PA} \mathrm{A}_{\mathrm{Up}}\right) / \mathrm{rD}-\mathrm{PA}_{\text {Down }}\right)$ for young (empty boxes) and older (striped boxes) participants for fast and slow movements. Whiskers represent $95 \%$ confidence interval. 
A

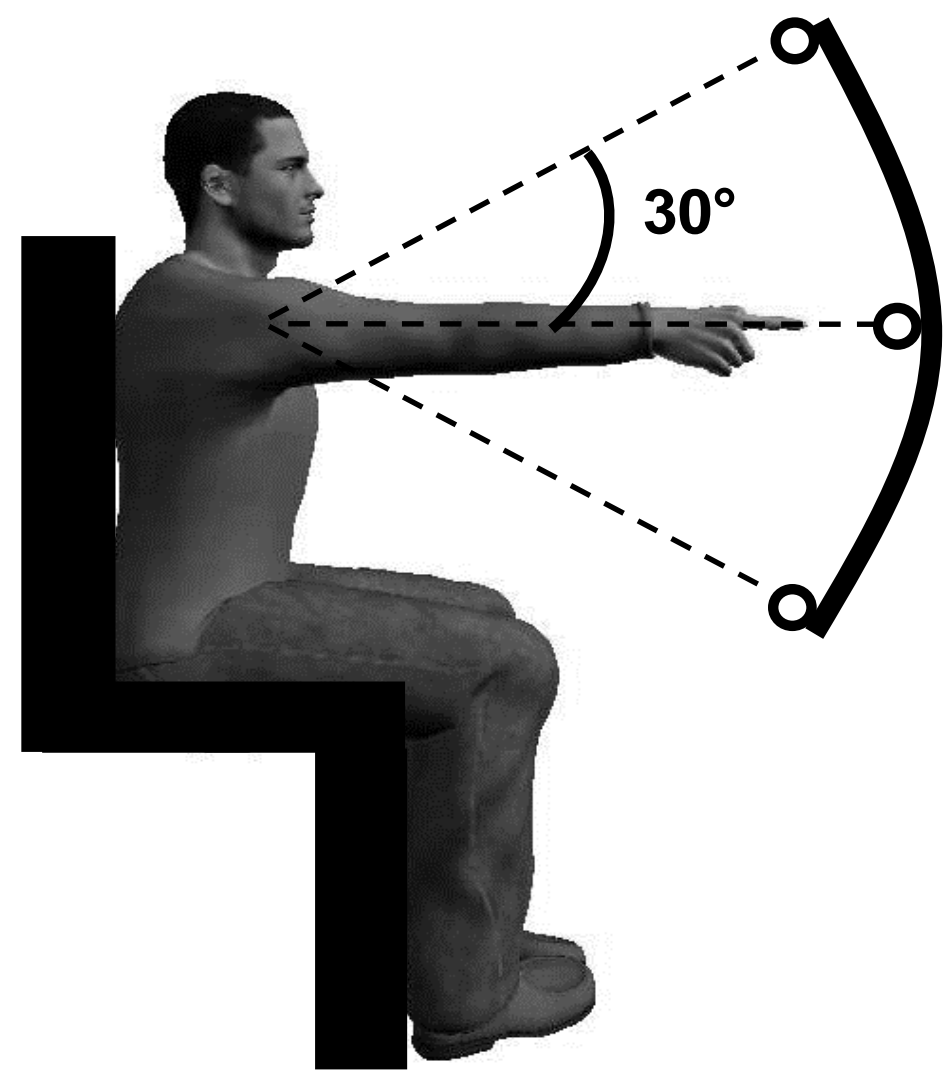

B

\section{Peak Velocity}

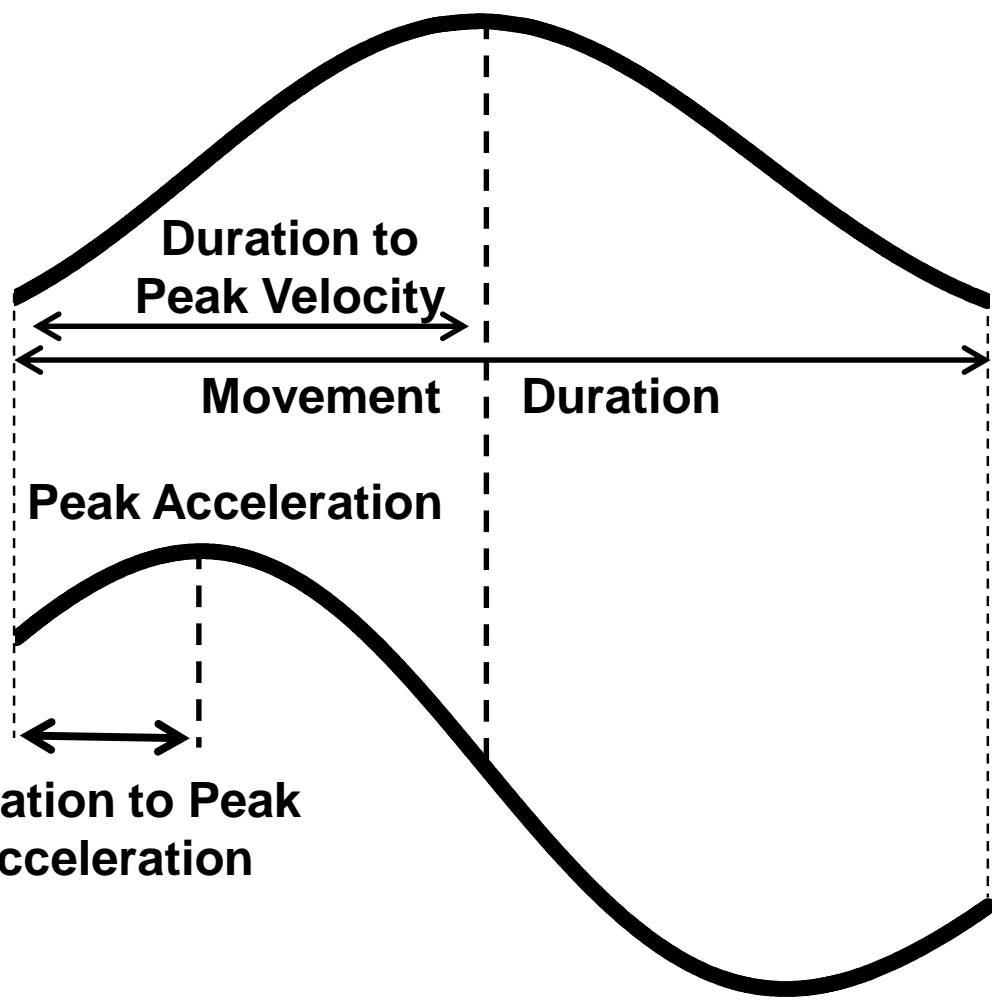




\begin{tabular}{|c|c|c|c|c|c|c|c|c|}
\hline & \multicolumn{4}{|c|}{ Fast } & \multicolumn{4}{|c|}{ Slow } \\
\hline & \multicolumn{2}{|c|}{ Young } & \multicolumn{2}{|c|}{ Older } & \multicolumn{2}{|c|}{ Young } & \multicolumn{2}{|c|}{ Older } \\
\hline & Up & Down & Up & Down & Up & Down & Up & Down \\
\hline $\begin{array}{c}\text { Movement } \\
\text { Duration (ms) }\end{array}$ & $328 \pm 31$ & $330 \pm 30$ & $349 \pm 52$ & $347 \pm 51$ & $570 \pm 147$ & $573 \pm 145$ & $581 \pm 115$ & $578 \pm 135$ \\
\hline Amplitude $\left(^{\circ}\right)$ & $29.6 \pm 1.1$ & $29.0 \pm 1.1$ & $29.2 \pm 1.7$ & $30.3 \pm 2.5$ & $28.4 \pm 1.4$ & $28.2 \pm 1.1$ & $27.6 \pm 2.1$ & $27.9 \pm 2.0$ \\
\hline rD-PA & $0.23 \pm 0.01$ & $0.24 \pm 0.01$ & $0.20 \pm 0.03$ & $0.23 \pm 0.02$ & $0.19 \pm 0.04$ & $0.21 \pm 0.03$ & $0.18 \pm 0.03$ & $0.22 \pm 0.03$ \\
\hline rD-PV & $0.48 \pm 0.02$ & $0.49 \pm 0.02$ & $0.44 \pm 0.04$ & $0.47 \pm 0.03$ & $0.46 \pm 0.04$ & $0.47 \pm 0.04$ & $0.43 \pm 0.04$ & $0.47 \pm 0.04$ \\
\hline
\end{tabular}



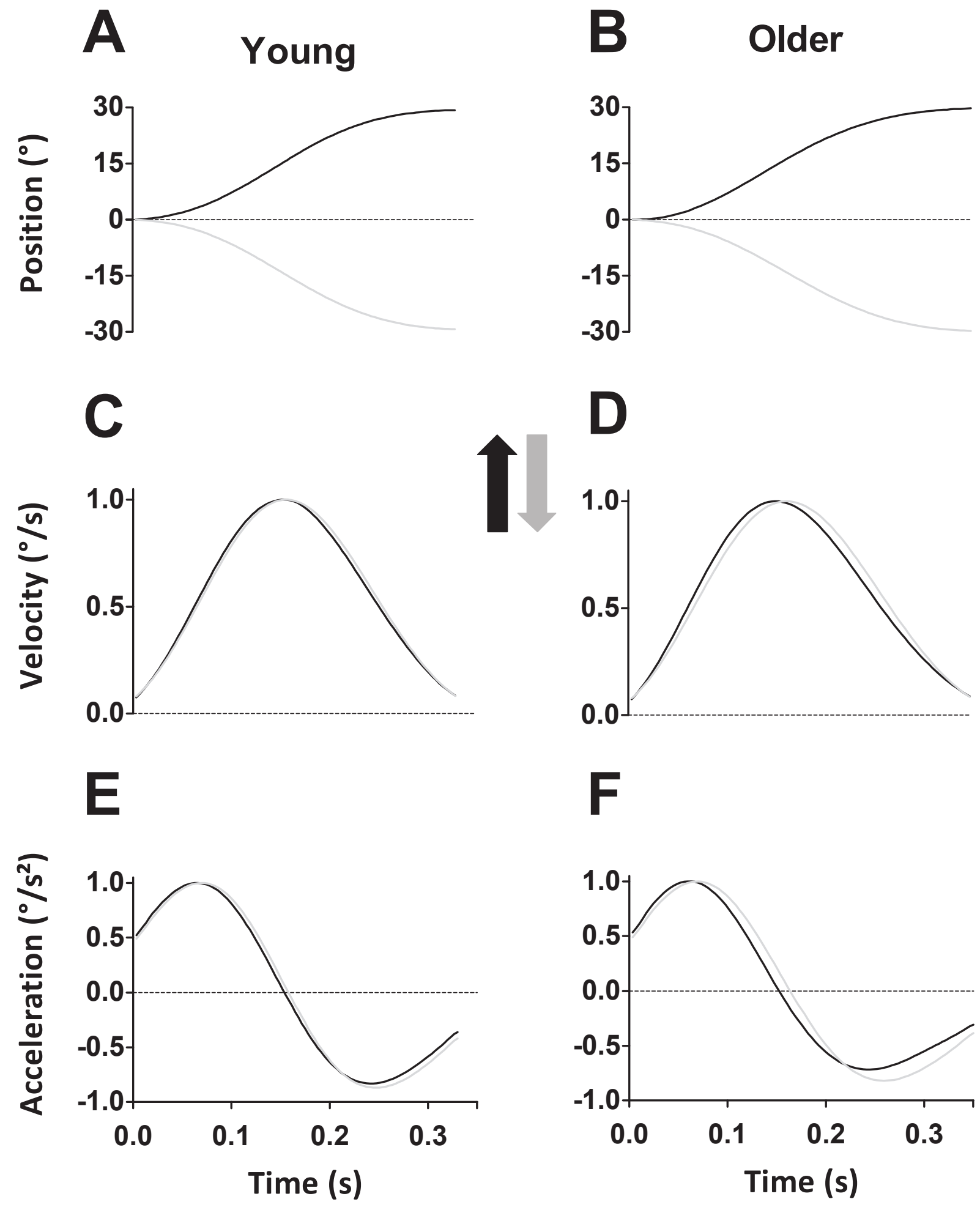

D
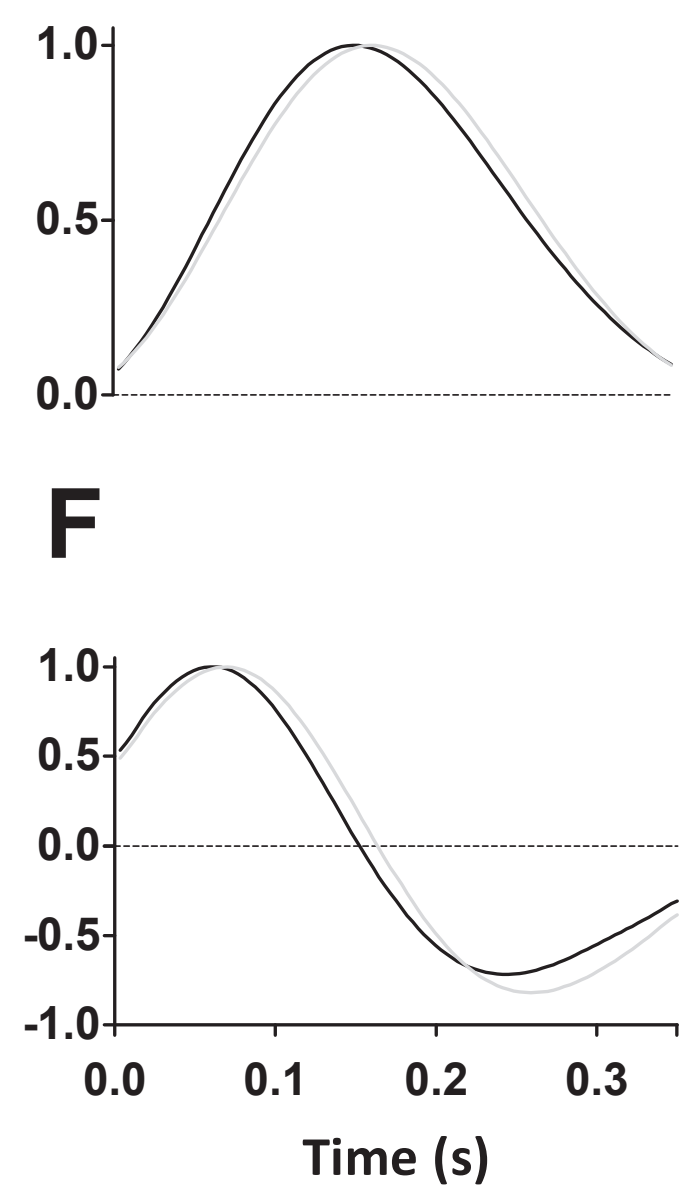


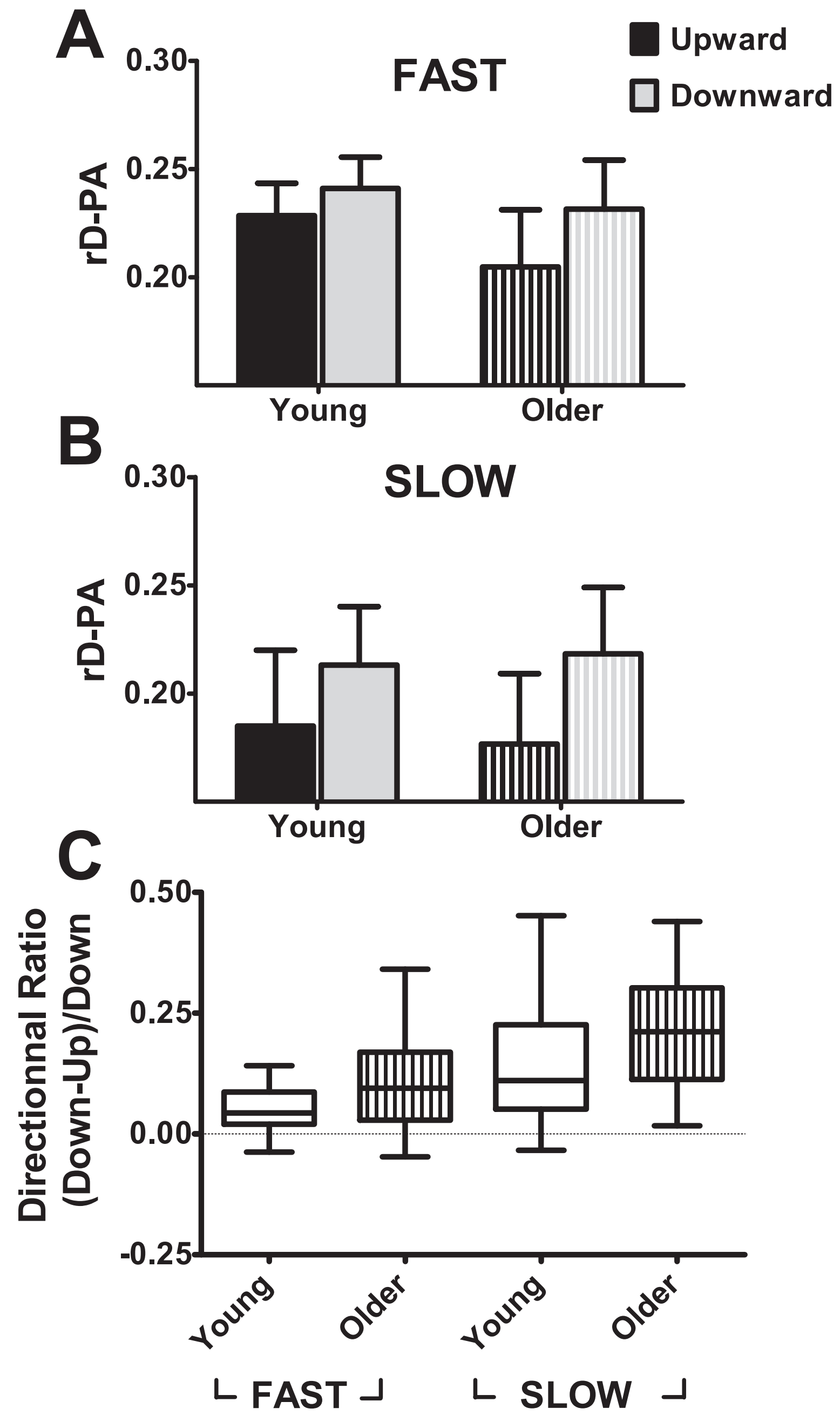

